\title{
The changing face
}

\section{of dental practice:}

emerging models of

\section{team care in Australia}

\section{Sydney-based researchers Grace Wong' and Michelle Irving' assess how}

\section{different skill-mix models have changed the face of the dental workforce.}

\section{Abstract}

Background Different skill-mix models have changed the face of the dental workforce. This study aimed to assess how this skill-mix translates into different practice models of care and the employerdentists' perception of the dental team.

Methods Twenty-two oral health therapists (OHTs) and 12 employer-dentists from both the private and public sectors participated in the online surveys. The OHT survey contained questions on practice models of care and work design characteristics. An open-ended question was added to the dentist survey assessing their perceptions of the OHTs in practice. Results OHTs provided over $90 \%$ of initial point-of-care for children and $40 \%$ for adults. All OHTs in the public sector and over $90 \%$ of the OHTs in private practice thought their job gave them a high degree of decision-making autonomy, despite over half of OHTs in private practice working under some level of supervision. Most employer-dentists perceived OHTs as an asset to their practice.

Conclusion The collaborative relationship has translated into different dental practice models of care. Dentists indicated that employing an OHT created efficiencies for their practice and OHTs reported they had a high degree of autonomy in the workplace, especially for the treatment of children. Further studies should be conducted to determine what influences the OHTs to exercise full autonomy. The impact of the changes in the oral health workforce will create adaptations in dental education in the future.

\section{Introduction}

The dental team professional mix and how oral healthcare services are delivered have changed and are continuing to change globally. Lack of access to oral healthcare was the primary trigger for the creation and expansion of educational and training of the allied oral health practitioners, such as dental therapists (DTs), dental hygienists (DHs) and, in recent years, oral health therapists $(\mathrm{OHTs})^{1,2}$ Allied oral health practitioners provide oral healthcare in both public clinics as well as private dental practices in several nations, such as England, New Zealand, Australia, Canada, the Netherlands, Singapore and Hong Kong SAR. ${ }^{3,4}$ Recently, the term 'skill-mix' has been used by policymakers to describe model dental practice with a whole array of team compositions and permutations to utilise these allied oral health practitioners to provide cost-efficient care. ${ }^{5,6}$ For example, screening of common oral diseases, routine care and preventive care for specific age groups are the scope of practice of these practitioners, which releases the dentist to perform more complex dental treatment. ${ }^{7,8,9,10}$

The allied oral health practitioners (DTs, DHs and OHTs) in Australia are primary healthcare providers who provide care in primary (general practice) and secondary (specialist practice) dental settings in both private and public sectors, as well as tertiary dental settings (specialist care in hospitals) in the public sector. OHTs must have met the education requirements in the dual streams of dental therapy and dental hygiene undergraduate courses accredited by the Dental Board Australia. There were 879 DTs, 1,453 DHs, 1,898 OHTs and 17,781 dentists in Australia in 2019, according to the Dental Board Registrant Data. ${ }^{11}$ The scope of practice regulation of the allied oral health practitioners varies among countries and in different settings. ${ }^{12,13,14}$ In Australia, the scope of practice regulation has

\section{Author information}

'The University of Sydney, Faculty of Medicine and Health, School of Dentistry, Australia . 
Fig. 1 Child models of care

\section{Child model of care 1}

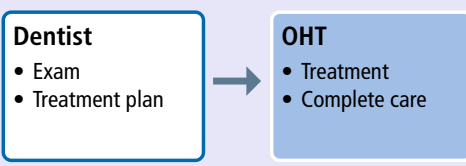

Child model of care 2

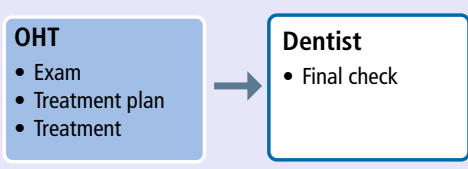

Child model of care 3

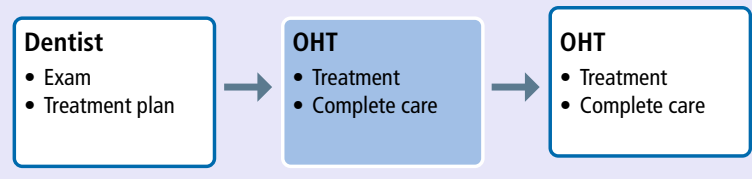

Child model of care 5

Dentist
- Exam
- Treatment plan
- Treatment
- Complete care

Child model of care 4

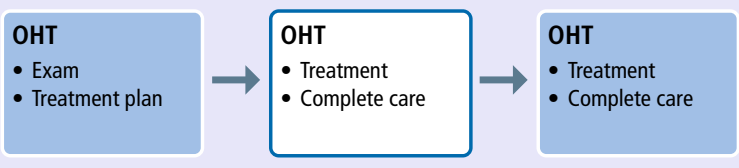

Fig. 2 Adult models of care

Adult model of care 1

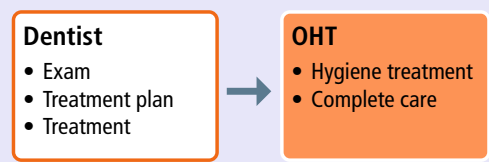

Adult model of care 2

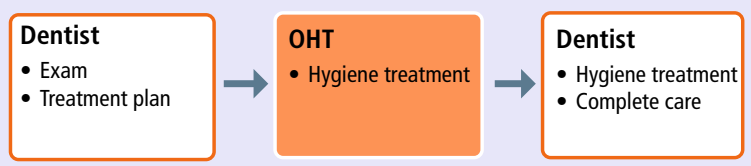

Adult model of care 3

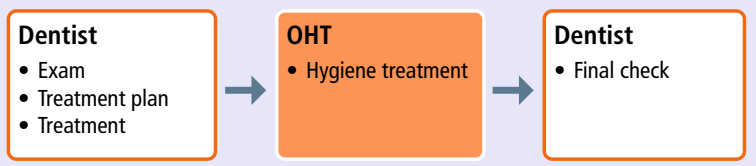

Adult model of care 4

\begin{tabular}{|l|l|}
\hline OHT \\
- Assess \\
- Dignostics \\
- Hygiene treatment
\end{tabular}$\rightarrow \begin{aligned} & \text { Dentist } \\
& \text { - Exam } \\
& \text { - Treatment plan } \\
& \text { - Treatment } \\
& \text { - Complete care }\end{aligned}$

gradually changed over time. Prior to 2012, the allied oral health practitioners provided patient care under 'supervision' of dentists. ${ }^{15}$ The Dental Board of Australia then replaced this requirement to 'practise oversight' with a need for allied practitioners to work with a dentist within a 'structured professional relationship', whereby the dentist is required to provide advice and care which falls outside of the scope of practice of the allied oral health practitioners. More recently in 2018, the board designed a new code of conduct, which defines standards of ethical and professional conduct for all oral health practitioners, in effect removing the 'structured professional relationship' between dentists and allied oral health practitioners. ${ }^{16}$ This substantial shift in the level of supervision has increased levels of independence in clinical decision-making and assigned the professional responsibility for patient care and safety to the allied oral health practitioners. This reform to promote working in a collaborative clinical environment and sharing of clinical decision-making has been encouraged by the National Workforce Strategic Framework and is gaining increasing prominence in healthcare policies. ${ }^{17}$

There are different models of care in dentistry across the world, but many studies only focus on productivity, efficiency and financial aspects of these models. A previous study from the US reported the support for extended employment of allied oral health practitioners as a new practice workforce model..$^{18}$ In England, a model of care based on remuneration to integrate dental therapists into the dental practice was reported, ${ }^{6}$ and in the US, there has been a discussion of a practice model of integrating expanded function of allied dental personnel for better productivity and efficiency. ${ }^{19}$ However, there is no published evidence to define the current collaborative relationship and the practice models of care within a dental team in the public sector and in private practices in Australia, to determine if models of care are changing to reflect the changes in governance and how this may affect patient care in the future. This study aimed to investigate how this relationship translates into different practice models of care, the perceptions of the allied oral health practitioners on autonomy support and the shared clinical decisionmaking process in their dental practice, and the dentists' perception of utilising these practitioners in the dental team.

\section{Methods}

This pilot study was approved by the University of Sydney Human Research Ethics Committee (2017/636). A convenience sample of 25 OHTs and their employer-dentists from 16 private dental practices and six public sector services, who were attending a continuing education course at the Sydney Dental School in October 2017, were invited to participate in this study. This course was established to extend the OHTs' skills in performing simple restorations on adult patients, which included eight days of lectures and eight days of simulation practice. The course participants were from New South Wales and Queensland. Separate survey instruments were designed for the OHTs and dentists, which were hosted by REDCap, ${ }^{20}$ and links were distributed via email. The OHT survey was in two sections: firstly, a demographic information section that collected data on elements such as years of working experience, the region of practice, type of service provided and practice models of care; secondly, the survey included an adaption of the task and knowledge characteristics of the 'Work Design Questionnaire, ${ }^{21}$ with only sections applicable to OHTs included. This questionnaire used a Likert scale to assess the OHT perceptions on the autonomy, support 
Fig. 3 The distribution of child practice models of care

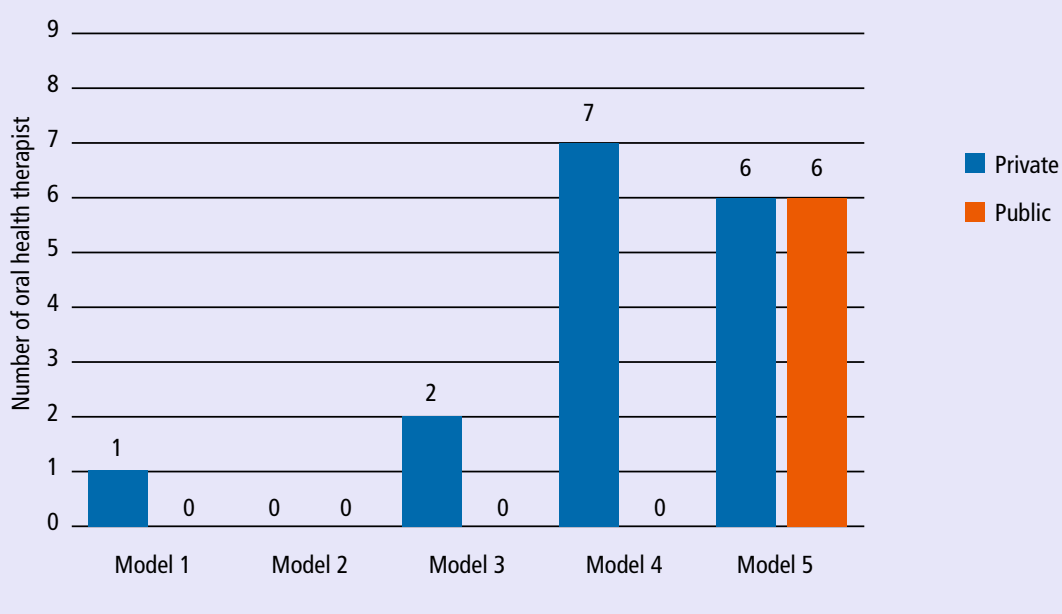

Fig. 4 The distribution of adult practice models of care

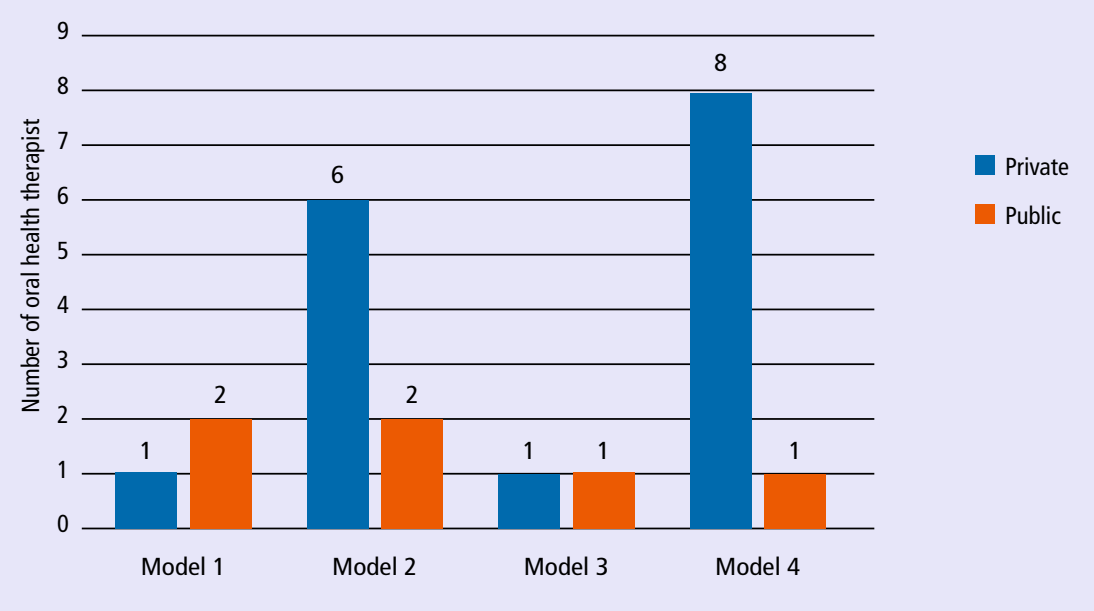

and shared decision-making process in the collaborative relationship. The employer-dentist survey shared the demographic information section, as in the OHT survey, but also included an open-ended question to assess the employerdentists' opinion of the OHTs in their practice.

To assist in data collection, potential 'models of care' were designed from knowledge within the profession and consultation with past oral health graduates to describe the flow of patients within a practice, for the course of care of both children and adults. There were five child models of care and four adult models of care options, as well as an 'other' option for participants to describe their own model if the options did not suit. The models of care are outlined in Figures 1 and 2, which include various patient and treatment pathways, from full autonomy to very little autonomy for the OHT.

Descriptive statistics were performed to analyse the practice models of care and to examine the characteristics of survey responses on the perception of autonomy support and the shared clinical decision- making process in the dental practice. Open-ended question responses from the employer-dentists were coded and analysed to answer the research question on the emerging practice models of care in dentistry.

\section{Results}

\section{OHTs' reported models of care}

Eighty-eight percent $(n=22)$ of all surveys were returned. Of these, 16 OHTs from private practices and six from public clinics responded to the surveys. Twenty-one were female and one was male, with the male participant from the public sector. Sixty-nine percent $(n=11)$ of participants from the private sector and $83 \%(n=5)$ of participants from the public sector worked $30-40$ hours per week. The rest of the participants worked less than 30 hours per week. In the private sector, $87 \%(n=14)$ of participants had less than ten years of working experience, while $13 \%(n=2)$ had over 15 years of working experience. In the public sector, all participants $(n=6)$ had less than ten years of working experience.

Forty-four percent $(n=7)$ of the OHTs in the private sector practised the 'child model of care 4' (1. OHT: examination, treatment plan; 2. Dentist: approve treatment plan; 3. OHT: deliver treatment). Thirty-eight percent $(\mathrm{n}=6)$ practised model 5 (OHT: examination, treatment plan, deliver treatment independently). Twelve percent $(n=2)$ practised model 3 (1. OHT: examination, treatment plan, deliver treatment; 2 . Dentist: final check), while only $6 \%(n=1)$ practised model 1 (OHT: deliver treatment prescribed by a dentist). In the public sector, all $(\mathrm{n}=6)$ OHTs practised model 5 (Fig. 3).

Fifty percent $(n=8)$ of private sector OHTs practised the 'adult model of care 4' (1. OHT: assessment, diagnostics, dental hygiene treatment; 2. Dentist: examination and other dental treatment). Thirty-eight percent $(n=6)$ practised model 2 (1. Dentist: examination; 2. OHT: dental hygiene treatment; 3. Dentist: other dental treatment). Of the remaining private sector OHTs, one practised model 1 (1. Dentist: examination and treatment; 2. OHT: dental hygiene treatment) and one practised model 3 (1. Dentist: examination and treatment; 2. OHT: dental hygiene treatment; 3. Dentist: final check). In the public sector, $33 \%(n=2)$ of OHTs practised model $1,33 \%(\mathrm{n}=2)$ practised model $2,6 \%$ $(\mathrm{n}=1)$ practised model 3 and $6 \%(\mathrm{n}=1)$ practised model 4 (Fig. 4)

Ninety-five percent $(\mathrm{n}=21)$ of OHTs provided initial point-of-care for children. All OHTs in the public sector provided treatment for children independently without treatment plan approval from the employer-dentists. Forty-one percent $(n=9)$ of OHTs provided an initial point-of-care for the adults for the purpose of providing assessments, diagnostics and dental hygiene treatment, before transferring patients to the employer-dentists.

\section{Work Design Questionnaire}

The two domains adapted from the Work Design Questionnaire (WDQ) were task characteristics and knowledge characteristics. Within the task characteristics, there were two components, namely work schedule autonomy and decision-making autonomy. Over $90 \%$ $(\mathrm{n}=15)$ of public sector OHTs and over $80 \%$ $(n=5)$ of private practice OHTs indicated that their job allowed them to make their own decisions in scheduling their own work and planning how they did their work. All OHTs in both private and public practices agreed that their job let them use their judgement in doing their work. All OHTs in the public sector and over $90 \%$ of the OHTs in private practice thought their job gave them freedom and independence to do their work. Within the knowledge characteristics domain, 


\section{Table 1 Task characteristics and knowledge characteristics - percentage of agreement (adapted from the WDQ) ${ }^{21}$}

\begin{tabular}{|c|c|c|c|c|c|c|c|}
\hline Characteristic & Statement & Sector & $\begin{array}{l}\text { Strongly } \\
\text { disagree }\end{array}$ & Disagree & Neutral & Agree & $\begin{array}{l}\text { Strongly } \\
\text { agree }\end{array}$ \\
\hline \multirow{6}{*}{$\begin{array}{l}\text { Task characteristics: } \\
\text { work schedule autonomy }\end{array}$} & \multirow{2}{*}{$\begin{array}{l}\text { My job allows me to decide on how I } \\
\text { schedule my work }\end{array}$} & Private & 0 & $1(6.25 \%)$ & 0 & $7(43.75 \%)$ & $8(50 \%)$ \\
\hline & & Public & 0 & 0 & $1(16.7 \%)$ & $2(33.3 \%)$ & $3(50 \%)$ \\
\hline & \multirow{2}{*}{$\begin{array}{l}\text { My job allows me to decide on the order } \\
\text { that things are done }\end{array}$} & Private & 0 & 0 & $2(12.5 \%)$ & $8(50 \%)$ & $6(37.5 \%)$ \\
\hline & & Public & 0 & 0 & $1(16.7 \%)$ & $4(66.7 \%)$ & $1(16.7 \%)$ \\
\hline & \multirow{2}{*}{$\begin{array}{l}\text { My job allows me to plan how I do my } \\
\text { work }\end{array}$} & Private & 0 & 0 & 1 (6.25\%) & $6(37.5 \%)$ & $9(56.25 \%)$ \\
\hline & & Public & 0 & 0 & $1(16.7 \%)$ & $2(33.3 \%)$ & $3(50 \%)$ \\
\hline \multirow{6}{*}{$\begin{array}{l}\text { Task characteristics: } \\
\text { decision-making autonomy }\end{array}$} & \multirow{2}{*}{$\begin{array}{l}\text { My job lets me use my judgement in } \\
\text { doing my work }\end{array}$} & Private & 0 & 0 & 0 & 9 (56.25\%) & $7(43.75 \%)$ \\
\hline & & Public & 0 & 0 & 0 & $2(33.3 \%)$ & $4(66.7 \%)$ \\
\hline & \multirow{2}{*}{$\begin{array}{l}\text { My job allows me freedom and } \\
\text { independence to do my work }\end{array}$} & Private & 0 & $1(16.7 \%)$ & 0 & $6(37.5 \%)$ & $9(56.25 \%)$ \\
\hline & & Public & 0 & 0 & 0 & $2(33.3 \%)$ & $4(66.7 \%)$ \\
\hline & \multirow{2}{*}{$\begin{array}{l}\text { My job allows me to decide how to do } \\
\text { my work }\end{array}$} & Private & 0 & $1(16.7 \%)$ & 0 & $8(50 \%)$ & $7(43.75 \%)$ \\
\hline & & Public & 0 & 0 & $1(16.7 \%)$ & 2 (33.3\%) & $3(50 \%)$ \\
\hline \multirow{8}{*}{$\begin{array}{l}\text { Knowledge characteristics: } \\
\text { information processing }\end{array}$} & \multirow{2}{*}{$\begin{array}{l}\text { My job requires me to monitor a great } \\
\text { deal of information }\end{array}$} & Private & 0 & 0 & 0 & $9(56.25 \%)$ & $7(43.75 \%)$ \\
\hline & & Public & 0 & 0 & 0 & 2 (33.3\%) & $4(66.7 \%)$ \\
\hline & \multirow{2}{*}{$\begin{array}{l}\text { My job requires that I engage in a large } \\
\text { amount of thinking }\end{array}$} & Private & 0 & $1(16.7 \%)$ & 0 & $6(37.5 \%)$ & $9(56.25 \%)$ \\
\hline & & Public & 0 & 0 & 0 & $2(33.3 \%)$ & $4(66.7 \%)$ \\
\hline & \multirow{2}{*}{$\begin{array}{l}\text { My job requires me to keep track of } \\
\text { more than one thing at a time }\end{array}$} & Private & 0 & 1 (16.7\%) & 0 & $8(50 \%)$ & 7 (43.75\%) \\
\hline & & Public & 0 & 0 & $1(16.7 \%)$ & $2(33.3 \%)$ & $3(50 \%)$ \\
\hline & \multirow{2}{*}{$\begin{array}{l}\text { My job requires me to analyse a lot of } \\
\text { information }\end{array}$} & Private & 0 & $1(16.7 \%)$ & 0 & $6(37.5 \%)$ & 9 (56.25\%) \\
\hline & & Public & 0 & 0 & 0 & 2 (33.3\%) & $4(66.7 \%)$ \\
\hline \multirow{8}{*}{$\begin{array}{l}\text { Knowledge characteristics: } \\
\text { problem solving }\end{array}$} & \multirow{2}{*}{ My job involves solving problems } & Private & 0 & 0 & $1(16.7 \%)$ & $5(31.25 \%)$ & $10(62.5 \%)$ \\
\hline & & Public & 0 & 0 & 0 & $6(37.5 \%)$ & $6(37.5 \%)$ \\
\hline & \multirow{2}{*}{ My job requires me to be creative } & Private & 0 & $1(16.7 \%)$ & $3(18.75 \%)$ & $5(31.25 \%)$ & $7(43.75 \%)$ \\
\hline & & Public & 0 & 0 & 0 & $3(50 \%)$ & $3(50 \%)$ \\
\hline & \multirow{2}{*}{$\begin{array}{l}\text { My job requires dealing with problems } \\
\text { that I have not met before }\end{array}$} & Private & 0 & $3(18.75 \%)$ & $2(12.5 \%)$ & $7(43.75 \%)$ & $4(25 \%)$ \\
\hline & & Public & 0 & 0 & $1(16.7 \%)$ & $3(50 \%)$ & $2(33.3 \%)$ \\
\hline & \multirow{2}{*}{$\begin{array}{l}\text { My job requires unique ideas and } \\
\text { solutions to problems }\end{array}$} & Private & 0 & $1(16.7 \%)$ & $4(25 \%)$ & $6(37.5 \%)$ & $5(31.25 \%)$ \\
\hline & & Public & 0 & 0 & 0 & $4(66.7 \%)$ & $2(33.3 \%)$ \\
\hline \multirow{6}{*}{$\begin{array}{l}\text { Knowledge characteristics: } \\
\text { skill variety }\end{array}$} & \multirow{2}{*}{ My job requires a variety of skills } & Private & 0 & 0 & 0 & $6(37.5 \%)$ & $10(62.5 \%)$ \\
\hline & & Public & 0 & 0 & 0 & $1(16.7 \%)$ & $5(83.3 \%)$ \\
\hline & \multirow{2}{*}{$\begin{array}{l}\text { My job requires me to utilise a variety of } \\
\text { different skills to complete the work }\end{array}$} & Private & 0 & 0 & 0 & $7(43.75 \%)$ & $9(56.25 \%)$ \\
\hline & & Public & 0 & 0 & 0 & $3(50 \%)$ & $3(50 \%)$ \\
\hline & \multirow{2}{*}{$\begin{array}{l}\text { My job requires me to use a number of } \\
\text { complex or high-level skills }\end{array}$} & Private & 0 & 0 & $4(25 \%)$ & $5(31.25 \%)$ & $7(43.75 \%)$ \\
\hline & & Public & 0 & 0 & $2(33.3 \%)$ & $1(16.7 \%)$ & $3(50 \%)$ \\
\hline \multirow{8}{*}{$\begin{array}{l}\text { Knowledge characteristics: } \\
\text { specialisation }\end{array}$} & \multirow{2}{*}{$\begin{array}{l}\text { My job is highly specialised in terms of } \\
\text { purpose, tasks or activities }\end{array}$} & Private & 0 & 0 & 0 & $9(56.25 \%)$ & $7(43.75 \%)$ \\
\hline & & Public & 0 & 0 & 0 & $2(33.3 \%)$ & $4(66.7 \%)$ \\
\hline & The tools, procedures and materials & Private & 0 & 0 & $1(6.25 \%)$ & $6(37.5 \%)$ & $9(56.25 \%)$ \\
\hline & used on this job are highly specialised & Public & 0 & 0 & $4(66.7 \%)$ & 0 & $2(33.3 \%)$ \\
\hline & My job required specialised knowledge & Private & 0 & 0 & $1(6.25 \%)$ & $11(68.75 \%)$ & $4(25 \%)$ \\
\hline & and skills & Public & 0 & 0 & $1(16.7 \%)$ & $2(33.3 \%)$ & $3(50 \%)$ \\
\hline & My job requires a depth of knowledge & Private & 0 & 0 & 0 & $7(43.75 \%)$ & $9(56.25 \%)$ \\
\hline & and expertise & Public & 0 & 0 & $1(16.7 \%)$ & $3(50 \%)$ & $2(33.3 \%)$ \\
\hline
\end{tabular}


four components were adapted; these were information processing, problem-solving, skills variety and specialisation. All the OHTs in the public sector and over $90 \%$ in private practices perceived that their job required them to engage in a large amount of thinking. Over $80 \%(n=5)$ of OHTs in the public sector and nearly $70 \%(\mathrm{n}=11)$ of the OHTs in private practice reported that they were expected to deal with problems which they had not come across before. All OHTs perceived that their job required them to utilise a variety of different skills to complete their work. Nearly all OHTs agreed that their jobs required them to have a depth of knowledge and expertise (Table 1).

\section{Employer-dentists' reported models of} care and their perception of OHTS Fifty-five percent $(n=12)$ of the employerdentists returned their surveys; eight from the private sector and four from the public sector. All 12 dental practices, both private and public, employed a combination of DTs, DHs and OHTs. Fifty percent $(n=6)$ of the employer-dentists had over 20 years of working experience, $25 \%(n=3)$ had $10-20$ years of working experience, and the remaining dentists $(n=3)$ had less than ten years of experience.

The employer-dentists' open-ended question responses fell into two categories: increased efficiency in dental practice, and employee recognition and appreciations.

Increased efficiency in dental practice The employer-dentists valued the effort of the OHT in the dental team, which increased efficiency in the dental practice:

- Dentist 2 (private): 'Reduce patient waiting time'

- Dentist 3 (private): 'Relieve patient pressure from me, provide an explanation of treatment and gain informed consent'

- Dentist 6 (private): 'Free me to concentrate on more complex dental treatment'.

\section{Employee recognition and appreciations}

The employer-dentists recognised the importance of the skills of the OHTs, which ultimately benefited the practice and patients:

- Dentist 9 (private): 'Like a mini dentist for kids'

- Dentist 4 (public): 'Provide education and preventive treatment to our patients'

- Dentist 8 (public): 'Give patients more care and time compared to the dentist'

- Dentist 7 (public): 'Skilful in patient care and behavioural management'.

\section{Discussion}

This is the first study of its kind to investigate the working relationship between the employerdentists and OHTs in Australia. This pilot study demonstrated that allied oral health practitioners currently work collaboratively with their employer-dentists to coordinate patient care, in order to promote effective practices no matter which practice models of care they followed. They are moving towards a higher level of autonomy and greater independence in their treatment planning and delivery. Previously, employer-dentists were perceived to have a director role within the 'supervision' relationship, where they considered themselves as the primary decision-makers and believed that they were ultimately responsible for the care of the patients, which paralleled the historical nurse-doctor relationship. ${ }^{21}$ The hierarchical nature of working in a 'supervision' relationship is now changing to more of a collaborative team approach, with both the employer-dentists and the allied oral health practitioners being recognised as contributing their knowledge and skills to patient care, experiencing less defined professional boundaries, indicating that the dental profession is progressing at pace with other health professions.

The practice models of care for children and adults in this study indicated that the majority of OHTs were working independently in decision-making for their patients, with only a few working with prescriptive treatment directed by the employer-dentists. The employer-dentists were not the sole decisionmakers for the care of their patients. The allied oral health practitioners had the support and autonomy for shared decisionmaking for patient care with their employerdentists. In the public sector, all the OHTs had the autonomy to fully exercise their scope of practice, which allowed them to practise independent decision-making for child patients (child model of care 5). However, only about $50 \%$ of OHTs in private practice were given this full autonomy; they could only provide treatment for children according to a treatment plan approved by the employerdentists. It is possible that the number of years of working experience of the OHTs might have influenced the practice models of care. The recent change in policy to remove the 'structured professional relationship' within the dentistry workforce may affect the level of autonomy experienced by OHTs in the future.

The WDQ, which has been tested in 22 occupation categories, shows that professional occupations are expected to have a higher level of knowledge characteristics and autonomy than the jobs in non-professional occupations. ${ }^{22}$ The results in this study demonstrated a high level of agreement on those categories; the majority of the allied oral health practitioners perceived they had a high degree of trust and autonomy from their employer-dentists. Although questionnaires using the Likert scale only provide a unidimensional quantitative estimated measure of participants' agreement with a given statement and are prone to central tendency bias, ${ }^{23}$ we can speculate that this may be a feature of the collaborative relationship between the employer-dentists and the allied oral health practitioners based on our findings.

The changing context for the oral health workforce in Australia is now characterised by a significantly increased number of allied oral health practitioners who are becoming more accepted as part of the dental team. ${ }^{24}$ This is also reflected in the global literature. Previous research has shown that it was more costeffective for some treatment to be carried out by allied oral health practitioners. ${ }^{13,19,25,26,27}$ The employer-dentists also recognised the OHT skills and claimed that having the $\mathrm{OHT}$ in the team increased the efficiency of their dental practice.

With the addition of allied oral health practitioners, dentists are moving to utilise the therapists to do most routine care, leaving more advanced procedures for themselves as per findings from this study. At the same time, there is a high demand for entry into postgraduate courses and continuing education courses to extend their skills for restorative work in adults, in response to the changed models of care delivery in recent years. If this current trend continues, the dentists may become more of a 'specialist' to perform advanced procedures. ${ }^{28}$ Expanding the use of allied oral health practitioners would improve access and impact of oral healthcare delivery. ${ }^{29,30}$ This model of care would also have repercussions for the future of dental education for this emerging model of care, which focuses on equity access and cost-efficiency. We can also speculate that this may lead to changes in course curriculum and integrating collaborative learning in dentistry and oral health programmes.

The effect of the 2018 changes to the code of practice, which removes the 'structured professional relationship' between dentists and the OHT, should be evaluated in further studies such as these in the future.

\section{Limitations}

The sample size of this pilot study is relatively small and selection was based on participants in a continuing education course. As with any research, self-reporting could be biased as individuals may tend to overestimate or underestimate their responses. Generalisability 
should be considered with care as the survey was conducted with dual-skilled OHTs, which may not be applicable to single-skilled DTs or DHs. Due to the anonymous online survey, the practice models of care data from the employerdentists were not able to be linked to that of the OHTs, which did not allow for cross-validation. However, the OHTs provided comprehensive information in their surveys, which generated a good overview of the current skill-mix models. Future studies should be undertaken with a larger sample size and should include the whole aspect of the profession. The success of the method used in this pilot study will enable this to be undertaken.

\section{Conclusion and future research implications}

This study offers an insight into the current collaborative relationship between the employerdentists and the allied oral health practitioners in Australia. Employer-dentists recognise the skills of the OHTs and appreciate the efficiencies they provide to their practice. In general, more OHTs work collaboratively than under 'supervision'. All OHTs in the public sector had a higher level of autonomy, especially for treating child patients, compared with only half of OHTs in private practice. The most recent policy changes may further influence the changing face of the profession. The impact of the changes in the oral health workforce will have repercussions for dental education of all oral health professionals in the future.

\section{Acknowledgements}

The authors would like to thank Dr Marc Tennant, Winthrop Professor, Faculty of Science, School of Human Sciences, The University of Western Australia, Perth, Australia, for his support and expert opinion on this topic.

\section{Conflict of interest}

The authors report no conflict of interest.

This article was originally published in the $\mathrm{BDJ}$ on 22 May 2020 (Volume 228 pages 767-772).

\section{References}

1. Koppelman J, Singer-Cohen R. A Workforce Strategy for Reducing Oral Health Disparities: Dental Therapists. Am J Public Health 2017; DOI: 10.2105/AJPH.2017.303747.

2. Ross M K, Ibbetson R J, Turner S. The acceptability of dually-qualified dental hygienist-therapists to general dental practitioners in South-East Scotland. Br Dent J 2007; DOI: 10.1038/bdj.2007.45.

3. Nash D A, Friedman J W, Mathu-Muju $\mathrm{K} R$ et al. A review of the global literature on dental therapists. Community Dent Oral Epidemiol 2014; 42: 1-10.

4. Satur J G, Dewson B. A History of the Dental and Oral Heath Profession in Australia and
New Zealand. Aust N Zealand J Dent Oral Health Ther 2012; 1: 13.

5. Bullock A, Firmstone V. A professional challenge: the development of skill-mix in UK primary care dentistry. Health Serv Manage Res 2011; 24: 190-195.

6. Sun N, Harris R V. Models of practice organisation using dental therapists: English case studies. Br Dent J 2011; DOI: 10.1038/ sj.bdj.2011.624.

7. Gallagher J E, Kleinman E R, Harper P R. Modelling workforce skill-mix: how can dental professionals meet the needs and demands of older people in England? Br Dent J 2010; DOI: 10.1038/sj.bdj.2010.106.

8. Lamster I B, Eaves K. A model for dental practice in the 21st century. Am J Public Health 2011; 101: 1825-1830.

9. Macey R, Glenny A, Walsh T et al. The efficacy of screening for common dental diseases by hygiene-therapists: a diagnostic test accuracy study. J Dent Res 2015; DOI: 10.1177/0022034514567335.

10. Cannell P. Skill mix - a paradigm shift? $\mathrm{Br}$ Dent J 2016; 220: 307.

11. Dental Board of Australia. Registrant data - Reporting period: 01 July 2019 to 30 September 2019. 2019. Available online at https://www.dentalboard.gov.au/ AbouttheBoard/Statistics.aspx (accessed February 2019).

12. Satur J, Gussy M, Mariño R, Martini T. Patterns of Dental Therapists' Scope of Practice and Employment in Victoria, Australia. J Dent Educ 2009; 73: 416-425.

13. Gallagher J E, Lim Z, Harper P R. Workforce skill mix: modelling the potential for dental therapists in state-funded primary dental care. Int Dent J 2013; 63: 57-64.

14. Cowpe J, Barnes E, Bullock A. Skill-mix in dental teams in Wales. Vital 2013; 10: 38-43.

15. Australian Dental Association. Structured Professional Relationships. 2015. Available at https://www.ada.org.au/News-Media/ News-and-Release/Latest-News/StructuredProfessional-Relationships (accessed April 2020).

16. Dental Board of Australia. Code of conduct for registered health practitioners. 2014. Available online at https://www.dentalboard. gov.au/Codes-Guidelines/Policies-CodesGuidelines/Code-of-conduct.aspx (accessed April 2020).

17. Australian Health Ministers' Conference. National Health Workforce Strategic Framework. 2004. Available at https://www1. health.gov.au/internet/main/publishing.nsf/ Content/C66647AAB9871405 CA257BF000209A71/\$File/national_ strategic_health_workforce_framework.pdf (accessed April 2020).
18. McKinnon M, Luke G, Bresch J, Moss M, Valachovic R W. Emerging Allied Dental Workforce Models: Considerations for Academic Dental Institutions. J Dent Educ 2007; 71: 1476-1491.

19. Beazoglou T J, Chen L, Lazar V F et al. Expanded function allied dental personnel and dental practice productivity and efficiency. J Dent Educ 2012; 76: 1054-1060.

20. Harris P A, Taylor R, Thielke R, Payne J, Gonzalez N, Conde J G. Research electronic data capture (REDCap) - a metadata-driven methodology and workflow process for providing translational research informatics support. J Biomed Inform 2009; 42: 377-381.

21. House S, Havens D. Nurses' and Physicians' Perceptions of Nurse-Physician Collaboration: A Systematic Review. J Nurs Admin 2017; 47: 165-171.

22. Morgeson F P, Humphrey S E. The Work Design Questionnaire (WDQ): developing and validating a comprehensive measure for assessing job design and the nature of work. J Appl Psychol 2006; 91: 1321-1339.

23. Douven I. A Bayesian perspective on Likert scales and central tendency. Psychon Bull Rev 2018; 25: 1203-1211.

24. Balasubramanian M, Teusner D N. Dentists, specialists and allied practitioners in Australia: Dental Labour Force Collection, 2006. 2011. Available online at https://www. aihw.gov.au/reports/dental-oral-health/ dental-labour-force-collection-2006 (accessed April 2020).

25. Guay A H, Lazar V. Increasing productivity in dental practice: the role of ancillary personnel. J Am Coll Dent 2012; 79: 11-17.

26. Darling B G, Kanellis M J, McKernan S C, Damiano P C. Potential utilization of expanded function dental auxiliaries to place restoratives. J Public Health Dent 2015; 75: 163-168.

27. Lazar V F, Guay A H, Beazoglou T J. Economic Impact of Dental Hygienists on Solo Dental Practices. J Dent Educ 2012; 76: 1045-1053.

28. Thierer T E, Meyerowitz C. Trends in Generalist and Speciality Advanced Dental Education and Practice, 2005-06 to 2015-16 and Beyond. J Dent Educ 2017; DOI: 10.21815/JDE.017.023.

29. Balasubramanian M, Brennan D S, Short S D, Gallagher J E. A strife of interests: A qualitative study on the challenges facing oral health workforce policy and planning. Health Policy 2019; 123: 1068-1075.

30. Weintraub J A. What Should Oral Health Professionals Know in 2040: Executive Summary. J Dent Educ 2017; 81: 1024-1032.

https://doi.org/10.1038/s41407-020-0340-y 